Research Article

\title{
Study on the Model Test of the Antibreaking Effect of Fiber Reinforced Concrete Lining in Tunnel
}

\author{
Guang-yao Cui $\mathbb{D},{ }^{1}$ Xue-lai Wang $\mathbb{D}^{1},{ }^{1}$ and Dao-yuan Wang $\mathbb{D}^{2}$ \\ ${ }^{1}$ School of Civil Engineering, North China University of Technology, Beijing 100144, China \\ ${ }^{2}$ Department of Civil Engineering, Hebei Jiaotong Vocational and Technical College, Shijiazhuang, Hebei 050091, China \\ Correspondence should be addressed to Xue-lai Wang; jjlam124@163.com
}

Received 28 December 2019; Revised 22 July 2020; Accepted 1 October 2020; Published 15 October 2020

Academic Editor: Fabio Rizzo

Copyright ( $(2020$ Guang-yao Cui et al. This is an open access article distributed under the Creative Commons Attribution License, which permits unrestricted use, distribution, and reproduction in any medium, provided the original work is properly cited.

In order to study the antibreaking effect of the fiber reinforced concrete lining in the tunnel, this paper takes the a subway tunnel engineering project in $\mathrm{F}_{2-3}$ section of Jiujiawan fault as the research background and carries out the antibreaking model test of the fiber reinforced concrete lining in the active fault zone of high earthquake intensity. The results show that the antibreaking effect of the principle stress and the longitudinal strain of the fiber reinforced concrete lining are $30 \% \sim 40 \%$ and $80 \% \sim 90 \%$, respectively, and the minimum value of the structural safety factor is increased by $4 \sim 5$ times. The antibreaking effect of hybrid fiber reinforced concrete lining is better than that of steel fiber reinforced concrete lining. The safety of steel polypropylene hybrid fiber reinforced concrete tunnel lining is the highest, and its minimum structural safety factor is 1.62 . In the aspect of improving the antibreaking effect of the tunnel, the toughening effect of fiber reinforced concrete is stronger than that of reinforcing. The research results are of great significance to improve the antibreaking effect of tunnels in active fault areas with high earthquake intensity.

\section{Introduction}

In recent years, the development trend of tunnel engineering is rapid. More and more tunnel projects, even under extreme conditions, have been put into use and operation. In fact, the transportation infrastructure construction in western China continues to develop in depth, and traffic tunnels in active fault zones with high earthquake intensity continue to emerge, such as the Erlangshan Tunnel of Yakang Expressway (crossing Luding, Erlangshan, and Baohuang faults), Lanjiayan Tunnel of Mianyang-Maoxian Highway (crossing Longmenshan branch fault), series of tunnels of Lhasa-Shigatse Railway (crossing the Yajiang deep and large faults, and the northern bank of the Yajiang river), and series of tunnels of Sichuan-Tibet railway (crossing the Longmenshan, Xianshuihe, Jinsha River, Nujiang, and Yarlung Zangbo Rivers).

Strong earthquakes induced the activation of active faults and caused stick-slip dislocation, causing severe damage to the tunnel structure [1]. How to improve the seismic safety and stability of a traffic tunnel in the active fault zone with high earthquake intensity is one of the key technical problems to be studied and solved in the next research stage. Measures to improve the antibreaking performance of tunnels include strengthening of surrounding rocks, strengthening of structures, setting of reducing dislocation layers, setting of reducing dislocation joints, and use of large damping support structures. The tunnel lining structure is resistant to the effects of stick-slip dislocation of the fault, which requires the lining structure to have good shear, impact, bending and tensile properties. Fiber reinforced concrete has become an advantageous material for lining structures to resist stick-slip dislocation due to its excellent properties of reinforcement, toughness, and crack resistance [2].

At present, steel fiber is widely used, but the density of steel fiber is large, and the distribution of steel fiber in concrete is extremely uneven, which affects the performance of fiber to a certain extent, so it can be mixed with other fibers with low density. When two or more kinds of fibers are mixed into concrete, the positive hybrid effect can be exerted at different stages and levels. Hybrid fiber concrete can not 
only play the role of multidirectional constraint of high elastic modulus and high density fiber (steel fiber) but also play the role of crack resistance of low elastic modulus and low density fiber (polypropylene, basalt, etc.) [3].

Relevant experts and scholars at home and abroad have made some research on the antibreaking technology of tunnels in active fault zones with high earthquake intensity. The main research contents include the following parts. Experts such as Xiong et al. used numerical simulation and model tests to study the mechanical response and damage mechanism of stick-slip dislocation of the fault $[4,5]$. Russo et al. relied on the Bolu Tunnel and the Kohhrangs Tunnel, respectively, and used numerical simulation methods to carry out a comparative study on the effect of reducing dislocation joints with different pitch-span ratios on the secondary lining $[6,7]$. Liu et al. and other experts used the model test to study the antibreaking effect of the measures of reducing dislocation joints, reducing dislocation layers, and thickening the secondary lining [8-10]. Using the method of theoretical analysis and model test, Wang et al. and other experts studied the damping model, damping mechanism, fault, and parameter sensitivity of the damping layer [11-13]. Experts such as Cui et al. studied the basic mechanical properties of steel fiber and basalt fiber concrete and the static bearing properties of the lining by means of specimen test and model test $[14,15]$. To sum up, the research on antibreaking technology of tunnel mainly focuses on reducing dislocation joints at present, while the research on reducing dislocation layers is not comprehensive enough, and there are few reports on structural strengthening. In this paper, based on a subway tunnel engineering in $\mathrm{F}_{2-3}$ section of Jiujiawan fault, the model test research on the antibreaking performance of the fiber reinforced concrete lining in active fault zone with high earthquake intensity is carried out, which is of great significance to improve the safety and stability of the traffic tunnel structure in the mountainous area with high earthquake intensity.

\section{Basic Mechanical Properties of Fiber Reinforced Concrete}

2.1. Test Purpose and Grouping. In order to study the reinforcement and toughness mechanical properties of fiber reinforced concrete, plain concrete, steel fiber reinforced concrete (SFRC), steel basalt hybrid fiber reinforced concrete (SBFRC), and steel polypropylene hybrid fiber reinforced concrete (SPFRC) were tested. The tensile strength of steel fiber, basalt fiber, and polypropylene fiber is $1200 \mathrm{MPa}$, $565 \mathrm{MPa}$, and $4000 \mathrm{MPa}$, respectively, and the elastic modulus is $200000 \mathrm{MPa}$, $5900 \mathrm{MPa}$, and $105000 \mathrm{MPa}$, respectively. All the tests were carried out in reference to standard test methods for fiber reinforced concrete [16].

Through the cube compressive strength test and flexural strength test, the reinforcement performance was studied. The dimension of the cube compressive strength test piece was $100 \mathrm{~mm} \times 100 \mathrm{~mm} \times 100 \mathrm{~mm}$ and the size of the flexural test piece was $100 \mathrm{~mm} \times 100 \mathrm{~mm} \times 400 \mathrm{~mm}$. The toughness performance of the plate was studied by energy toughness test. The specimen size was $500 \mathrm{~mm} \times 500 \mathrm{~mm} \times 100 \mathrm{~mm}$.
Because the failures load of plain concrete specimen was small in the process of energy toughness test of large plate, the load of the specimen decreased rapidly after failure. Therefore, only SFRC, SBFRC, and SPFRC specimens were tested in this large plate energy toughness test. The fiber content of the test piece was designed according to the same volume ratio. The experimental grouping is shown in Table 1.

\subsection{Test Results and Analysis}

2.2.1. Cube Compressive Strength and Flexural Strength Test. The cube compressive strength test was carried out with the YES-2000 digital pressure tester, and the flexural strength test was carried out with the YES-300 flexural tester (see Figure 1). In the cube compressive strength test, the side of the specimen is taken as the bearing surface, and the axis of the specimen should be aligned with the center of the pressing plate under the testing machine. The loading speed is $0.3 \sim 0.5 \mathrm{MPa} / \mathrm{s}$. When the specimen is close to failure, stop adjusting the throttle until the specimen is damaged. Finally, record the maximum load, accurate to $0.1 \mathrm{MPa}$. In the flexural strength test, the specimen is placed in the middle of two supports, and then the load is applied uniformly and continuously. The loading speed is $0.02 \sim 0.05 \mathrm{MPa} / \mathrm{s}$, and the load is continuously loaded until the specimen is destroyed. Finally, the maximum load is recorded. According to the Test Standard for Mechanical Properties of Ordinary Concrete [18], if nonstandard parts are used in the cube compressive test and flexural strength test, the conversion coefficient should be used in the calculation. When the cube specimen size is $100 \mathrm{~mm} \times 100 \mathrm{~mm} \times 100 \mathrm{~mm}$, the compressive strength size conversion coefficient is 0.9 . When the cube specimen size is $100 \mathrm{~mm} \times 100 \mathrm{~mm} \times 400 \mathrm{~mm}$, the conversion factor of the flexural strength size is 0.85 . The test results are shown in Tables 2 and 3.

According to Tables 2 and 3, compared with plain concrete, the compressive strength of SFRC cube was increased by $20.19 \%$, and the flexural strength was increased by 23.54\%; the compressive strength of SBFRC cube was increased by $17.11 \%$ and the flexural strength was increased by $21.30 \%$; the compressive strength of SPFRC cube was increased by $16.62 \%$ and the flexural strength was increased by $20.29 \%$. This shows that SFRC is better than SBFRC and SPFRC in the same volume of fiber, and SBFRC is better than SPFRC.

\subsubsection{Energy Toughness Test of Large Plate. The energy} toughness test of the large plate was carried out by $250 \mathrm{kN}$ ordinary hydraulic testing machine (see Figure 2). The test is loaded in the center of the plate. Steel backing plates are added between the upper and lower pressing plates of the testing machine, the rigid components, and the pressure sensor. The support of the plate is a square steel frame made of section steel, with the inner side length of $500 \mathrm{~mm}$, which has enough rigidity to ensure no additional deformation during the loading process. The steel loading cushion block has a square section and a side length of $100 \mathrm{~mm}$. First, we 
TABLE 1: Test grouping.

\begin{tabular}{lccc}
\hline Item & Compression test & Flexural test & Energy toughness test of large plate \\
\hline Plain concrete $(\mathrm{C} 25[17])$ & 3 groups & 3 groups & 0 groups \\
SFRC $\left(\mathrm{CF} 25,42 \mathrm{~kg} / \mathrm{m}^{3}\right)$ & 3 groups & 3 groups & 3 groups \\
SBFRC $\left(\mathrm{CF} 25\right.$, steel fiber $30 \mathrm{~kg} / \mathrm{m}^{3}+$ basalt fiber $\left.3.3 \mathrm{~kg} / \mathrm{m}^{3}\right)$ & 3 groups & 3 groups & 3 groups \\
SPFRC $\left(\mathrm{CF} 25\right.$, steel fiber $30 \mathrm{~kg} / \mathrm{m}^{3}+$ polypropylene fiber & 3 groups & 3 groups & 3 groups \\
$\left.0.67 \mathrm{~kg} / \mathrm{m}^{3}\right)$ & & \\
\hline
\end{tabular}

Note: the length of steel fiber is $30 \mathrm{~mm}$, with a diameter of $0.55 \mathrm{~mm}$; the length of basalt fiber is $30 \mathrm{~mm}$, with a diameter of $18 \mu \mathrm{m}$; the length of polypropylene fiber is $20 \mathrm{~mm}$, with a diameter of $26 \mu \mathrm{m}$.

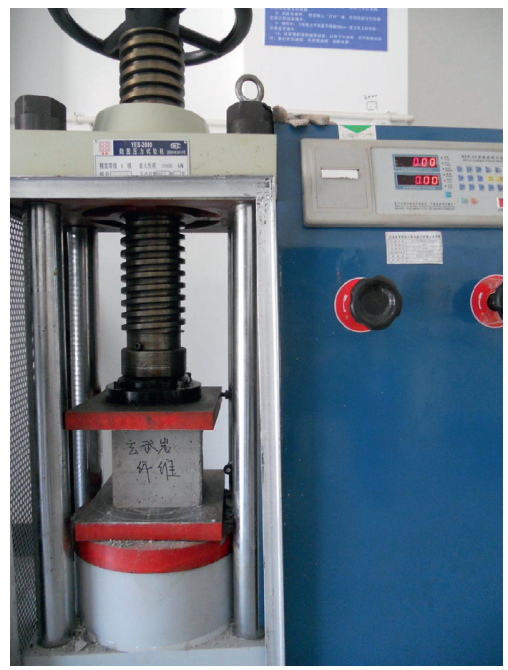

(a)

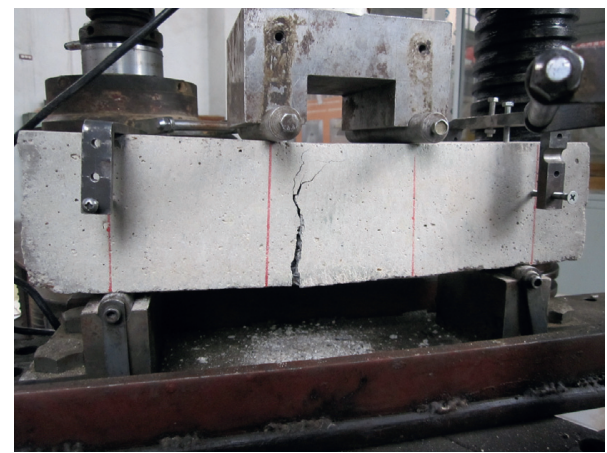

(b)

Figure 1: Test process. (a) Compressive strength test; (b) flexural strength test.

TABLE 2: Results of compressive test.

\begin{tabular}{lccc}
\hline Item & Test strength $(\mathrm{MPa})$ & Conversion strength $(\mathrm{MPa})$ & Percent growth (relative to plain concrete) \\
\hline Plain concrete & 28.691 & 25.822 & - \\
SFRC & 34.483 & 31.035 & 20.19 \\
SBFRC & 33.600 & 30.240 & 17.11 \\
SPFRC & 33.459 & 30.113 & 16.62 \\
\hline
\end{tabular}

TABle 3: Test results of flexural test.

\begin{tabular}{lccc}
\hline Item & Test strength $(\mathrm{MPa})$ & Conversion strength $(\mathrm{MPa})$ & Percent growth (relative to plain concrete) \\
\hline Plain concrete & 3.044 & 2.587 & - \\
SFRC & 3.760 & 3.196 & 23.54 \\
SBFRC & 3.692 & 3.138 & 21.30 \\
SPFRC & 3.661 & 3.112 & 20.29 \\
\hline
\end{tabular}

placed the supporting steel frame flat on the test bench, adjusted its levelness, and placed the test piece on the support; then, we started the hydraulic jack and used the constant speed displacement control $(1.5 \mathrm{~mm} / \mathrm{min})$ until the deflection of the central point of the square plate test piece reached $25 \mathrm{~mm}$; so far, the test was over. According to the load-deflection curve collected during the test process, the energy-deflection curve absorbed by the plate was calculated through the method of integral (see Figure 3), and then the energy absorbed by the plate could be obtained when the deflection at the center of the square plate was $25 \mathrm{~mm}$. In addition, the average value of the number of cracks in the specimen was counted, and the average value of the number of fibers at each crack was calculated. The test results are shown in Table 4.

It could be seen from Table 4 that the average maximum load of SFRC, SBFRC, and SPFRC were almost the same. For the number of cracks and the number of fibers in the cracks, SBFRC increased by $6.01 \%$ and $6.57 \%$, respectively, and SPFRC increased by $7.85 \%$ and $8.44 \%$, respectively. For the average value of absorbed energy, SBFRC increased by $13.84 \%$ and SPFRC increased by $18.42 \%$ compared with 


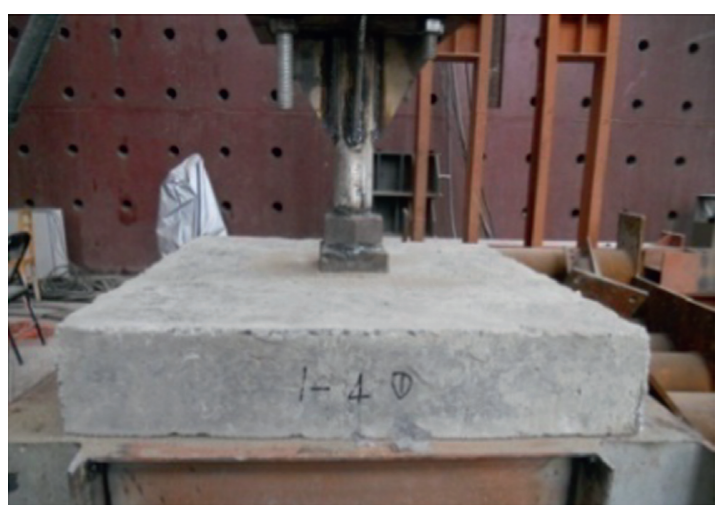

(a)

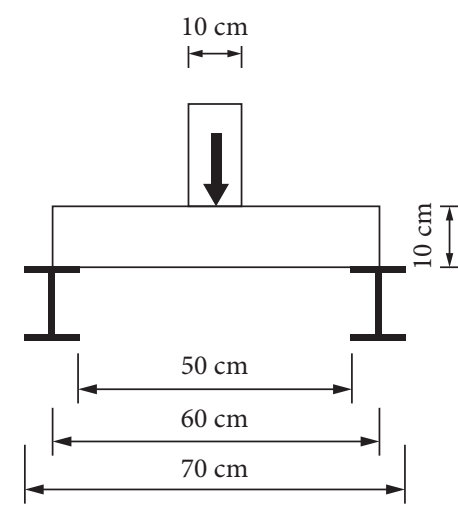

(b)

Figure 2: Energy toughness test of large plate. (a) Test photograph. (b) Test diagram.

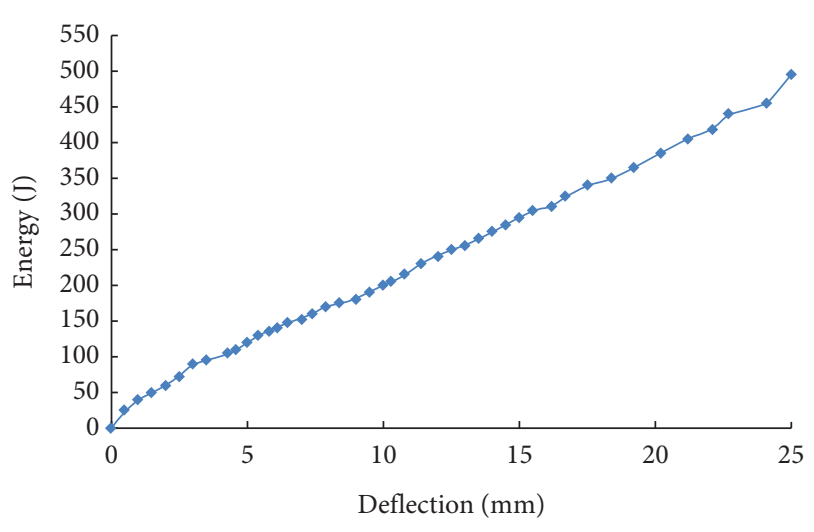

FIGURE 3: Energy-deflection curve.

SFRC. This shows that the toughening effect of SBFRC and SPFRC is better than that of SFRC, and the toughening effect of SPFRC is slightly better than that of SBFRC.

\section{Scheme Design of Antibreaking Model Test}

3.1. Overview of Supporting Projects. The total length of a metro line is $26.5 \mathrm{~km}$, with 21 stations. The line passes through four groups of active faults from south to north (see Figure 4). Based on the tunnel engineering in the $\mathrm{F}_{2-3}$ section of Jiujiawan fault, the model test was carried out. The fault is a Holocene Active normal fault with a dip angle of 70 degrees. The tunnel section is horse-shoe shaped, with a span of $8.573 \mathrm{~m}$ and a height of $9.120 \mathrm{~m}$. C25 shotcrete (with a thickness of $30 \mathrm{~cm}$ ) is used for the primary support, and C35 cast concrete (with a thickness of $60 \mathrm{~cm}$ ) is used for the secondary lining.

\subsection{Test Groups and Equipment}

3.2.1. Test Groups. In order to study the fault resistance of fiber reinforced concrete tunnel lining, four groups of indoor model tests were carried out. The test groups are shown in Table 5.

3.2.2. Test Equipment. The test was carried out by using the leaning straight stick-slip dislocation test box (designed by ourselves, length $\times$ wih $\times$ height $=2.5 \mathrm{~m} \times 2.5 \mathrm{~m} \times 2 \mathrm{~m}$ ). The test box is composed of the movable upper plate part and the fixed lower plate part. Referring to the $\mathrm{F}_{2-3}$ section of Jiujiawan fault, the dip angle here is 70 degrees (see Figure 5).

\subsection{Test Similar Ratio and Similar Materials}

3.3.1. Test Similar Ratio. According to the size of the tunnel and the test chamber and considering to eliminate the boundary effect of the test chamber as far as possible, the width of the test chamber should be greater than 7 times of the tunnel span, that is, the span of the tunnel model should be less than $2.5 / 7 \approx 0.357 \mathrm{~m}$, and the geometric similarity ratio should be greater than $8.573 / 0.357 \approx 24.01$, which is taken as 30. Considering the severe similarity matching, the elastic modulus similarity ratio is set to 45 . Other relevant physical quantities can be deduced according to the similarity theory [19], as shown in Table 6.

3.3.2. Test Similar Materials. The similar materials of surrounding rock are simulated by the hot-melt mixture of river sand, fly ash, and engine oil. The weight ratio of each component is determined by orthogonal test. The ratio of engine oil, river sand, and fly ash is $1: 3: 6$. See Table 7 for basic mechanical parameters of similar materials of surrounding rock.

Gypsum admixture (water cement ratio is 0.676) was used to simulate the secondary lining, and elastic modulus and compressive strength were used as similar control indexes. The secondary linings of SFRC, SBFRC, and SPFRC were simulated by adding steel fiber, basalt fiber, and polypropylene fiber to gypsum admixture in proportion. The waterproof board was simulated by polyethylene film. Two layers of PVC plastic plates (evenly coated with butter in the middle) were used to simulate the antibreaking effect of fault stick-slip dislocation (see Figure 6).

3.4. Arrangement of Test Measurement. The layout of the test measurement is shown in Figure 7. Micropressure box (Y, between the surrounding rock and primary support), transverse strain gauge $(\mathrm{H}$, inside and outside of the secondary lining are arranged in pairs), longitudinal strain 
TABLE 4: Results of energy toughness test of large plate.

\begin{tabular}{lcccc}
\hline Item & Maximum load $(\mathrm{kN})$ & Absorbed energy $(\mathrm{J})$ & Number of cracks & Number of fibers at cracks \\
\hline SFRC & 128.12 & 690.72 & 4.33 & 355.33 \\
SBFRC & 128.33 & 786.34 & 4.59 & 378.67 \\
Percentage increase of SBFRC over SFRC (\%) & 0.16 & 13.84 & 6.01 & 6.57 \\
SPFRC & 128.41 & 817.92 & 4.67 & 385.33 \\
Percentage increase of SPFRC over SFRC (\%) & 0.23 & 18.42 & 7.85 & 8.44 \\
\hline
\end{tabular}

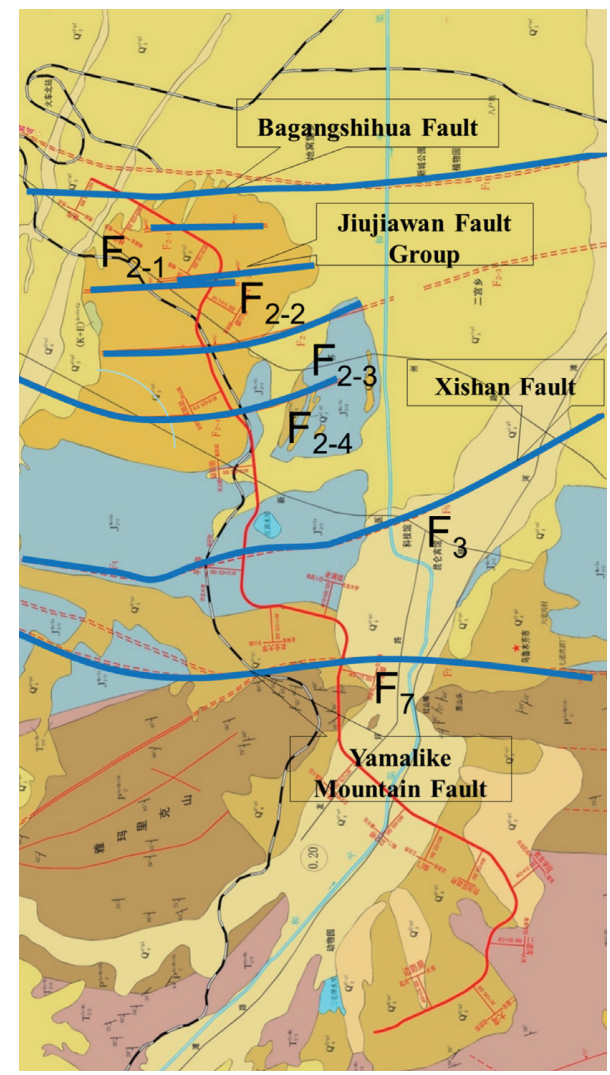

Figure 4: The geodetic structure of the line area.

TABLE 5: Test groups.

\begin{tabular}{|c|c|}
\hline $\begin{array}{l}\text { Working condition } \\
\text { number }\end{array}$ & Test contents \\
\hline 1 & The secondary lining is C25 concrete. \\
\hline 2 & $\begin{array}{l}\text { The secondary lining is CF25 steel fiber } \\
\text { concrete (SFRC) }\end{array}$ \\
\hline 3 & $\begin{array}{c}\text { The secondary lining is CF25 steel basalt } \\
\text { hybrid fiber concrete (SBFRC) }\end{array}$ \\
\hline 4 & $\begin{array}{c}\text { The secondary lining is CF25 steel } \\
\text { polypropylene hybrid fiber concrete } \\
\text { (SPFRC) }\end{array}$ \\
\hline
\end{tabular}

gauge (L, outside of the secondary lining), and right-angle strain flower ( $Z$, outside of the secondary lining) were arranged on the crown of each measurement section, and micropressure box was arranged in the middle of the side wall and the middle of the inverted arch.

The micropressure box is mainly used to test the contact stress between surrounding rock and supporting structure. The internal force of the structure is mainly measured by the

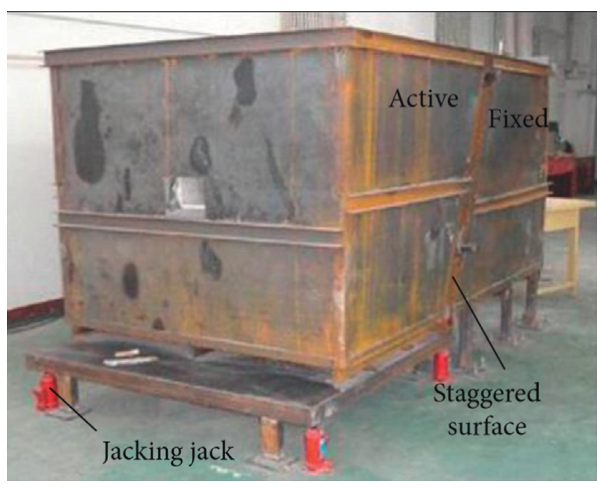

FIGURE 5: Leaning straight stick-slip dislocation test box.

lateral strain gauge arranged in pairs on the inner and outer sides of the secondary lining. The longitudinal strain gauge arranged outside the secondary lining mainly tests the longitudinal strain of the structure. The principle stress of the structure is tested by the right-angle strain flowers arranged outside the secondary lining.

\subsection{Test Process}

(1) A 5-ton jack was set at the bottom four corners of the upper plate of the test chamber to lift the upper plate of the chamber by $5 \mathrm{~cm}$ (displacement control is adopted based on which the ground displacement of the project is conservatively predicted to be $1.5 \mathrm{~m}$ in one hundred years).

(2) Fill and compact the similar materials of surrounding rock layer by layer ( $0.2 \mathrm{~m}$ for each layer) to the outer skin elevation of the tunnel invert, arrange the secondary lining model, waterproof board, and primary support, and install the micropressure box and other test sensors.

(3) At the same time, put down the four jacks at the bottom of the hanging wall. The hanging wall rock mass and the tunnel slipped along the dislocation surface. Collect the test data, and the test was finished.

\section{Test Data and Analysis of Antibreaking Model}

4.1. Principal Stress. The principle stress of the structure caused by the fault stick-slip dislocation was calculated by extracting the measurement data of the right-angle strain flowers of each measurement section after the test of each working condition (see Figure 8). The strain data is measured by right-angle strain flower, and then the stress is 
TABLE 6: Similarity ratio of other relevant physical quantities.

\begin{tabular}{lcc}
\hline Type & Physical quantities & Similarity coefficient \\
\hline \multirow{2}{*}{ Material properties } & Stress & 45 \\
& Strain/Poisson's ratio/internal friction angle & 1 \\
\hline \multirow{2}{*}{ Geometric characteristics } & Bulk density & 1.5 \\
& Cohesive force & 45 \\
\multirow{2}{*}{ Load } & Angular displacement/acceleration & 1 \\
& Area & 900 \\
& Load & 40500 \\
\end{tabular}

TABLE 7: Basic mechanical parameters of similar materials of surrounding rock.

\begin{tabular}{|c|c|c|c|c|}
\hline Parameter & $\begin{array}{l}\text { Modulus of elasticity } \\
(\mathrm{MPa})\end{array}$ & $\begin{array}{c}\text { Bulk density } \\
\left(\mathrm{kN} \cdot \mathrm{m}^{-3)}\right.\end{array}$ & $\begin{array}{l}\text { Cohesive force } \\
(\mathrm{kPa})\end{array}$ & $\begin{array}{l}\text { Internal friction angle } \\
\left({ }^{\circ}\right)\end{array}$ \\
\hline Prototype surrounding rock & $1300 \sim 1600$ & $17 \sim 20$ & $20 \sim 200$ & $20 \sim 27$ \\
\hline $\begin{array}{l}\text { Similar materials of surrounding } \\
\text { rock }\end{array}$ & 29.6 & 12.6 & 3.3 & 24.5 \\
\hline
\end{tabular}

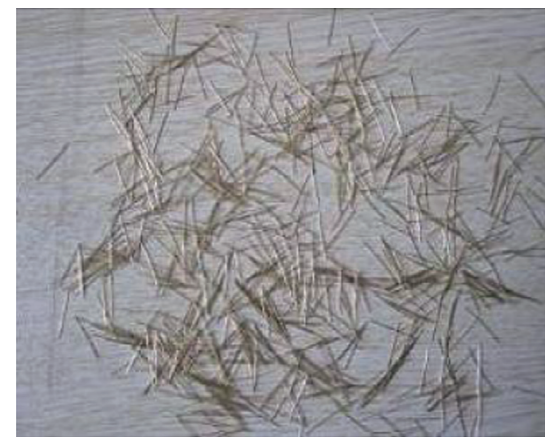

(a)

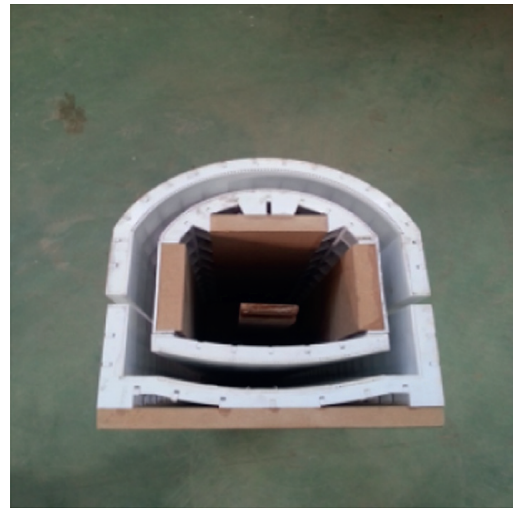

(d)

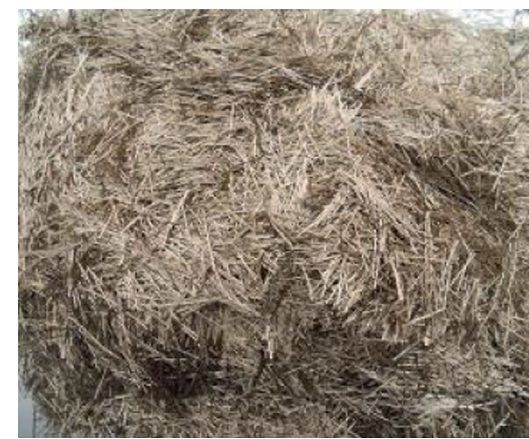

(b)

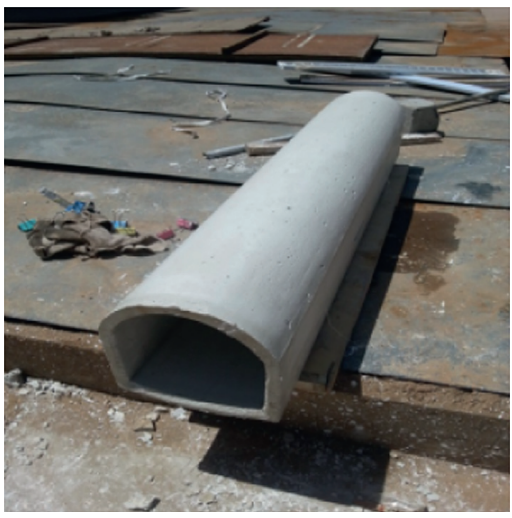

(e)

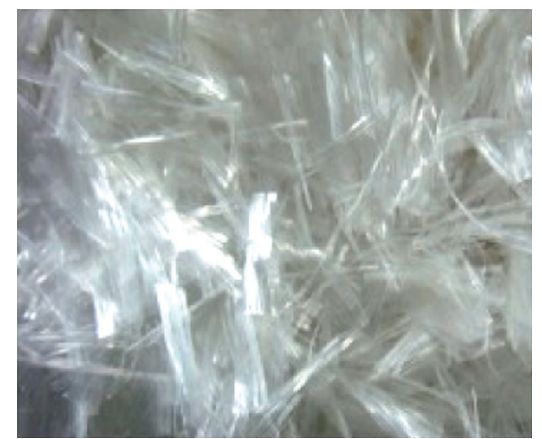

(c)

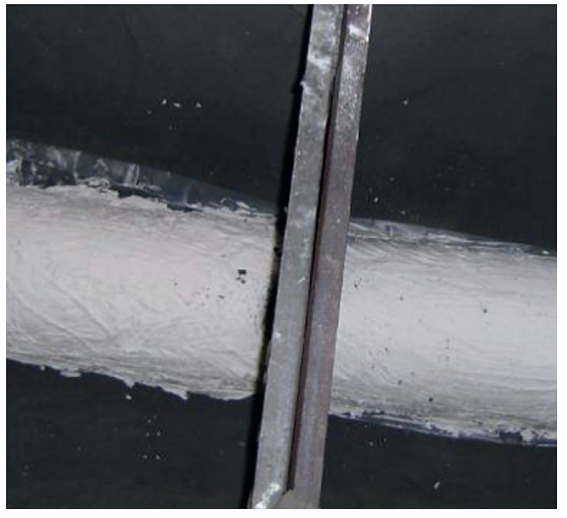

(f)

Figure 6: Test similar material and model. (a) Steel fiber. (b) Basalt fiber. (c) Polypropylene fiber. (d) Model casting. (e) Model of lining. (f) Waterproof board and primary support.

calculated according to the relationship between stress and strain, as shown in formula (1). The zero point of the abscissa is the intersection point of the tunnel height and the fault section (see Figure 6(a)), the positive part is the upper part, and the negative part of the abscissa is the footwall (the same as below):

$$
\frac{\sigma_{1}}{\sigma_{3}}=\frac{E\left(\varepsilon_{0}+\varepsilon_{90}\right)}{2(1-\mu)} \pm \frac{\sqrt{2} E}{2(1+\mu)} \sqrt{\left(\varepsilon_{0}-\varepsilon_{45}\right)^{2}+\left(\varepsilon_{45}-\varepsilon_{90}\right)^{2}} .
$$

In the formula, $\sigma_{1}$ represents the first principal stress, $\sigma_{3}$ represents the third principal stress, $E$ represents the elastic 


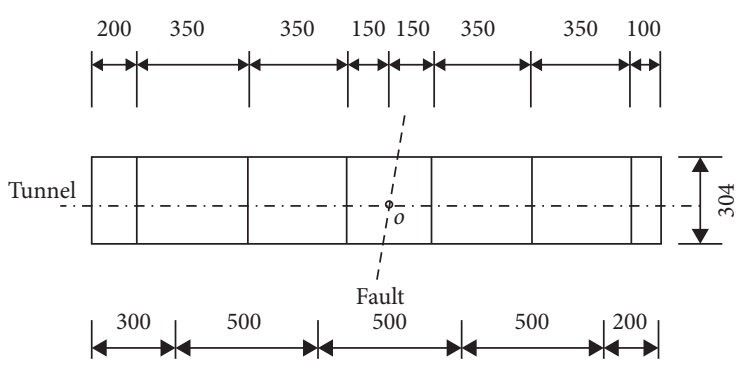

(a)

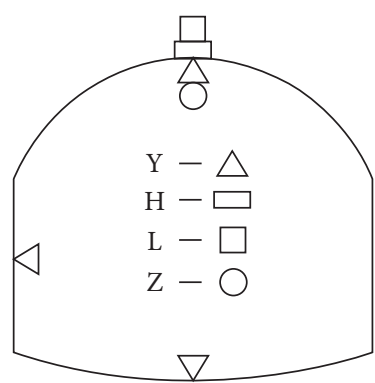

(b)

FIgURE 7: Arrangement of test measurement. (a) Measuring section (unit: mm). (b) Layout of measuring points.

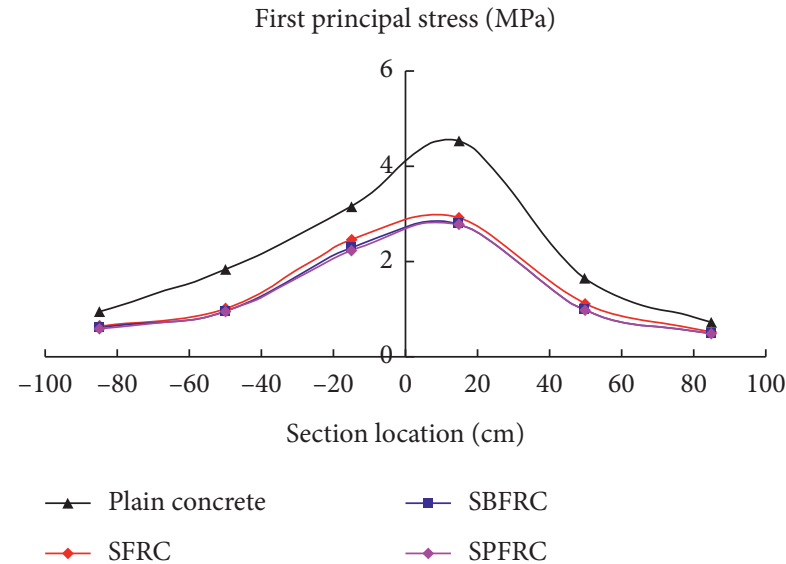

(a)

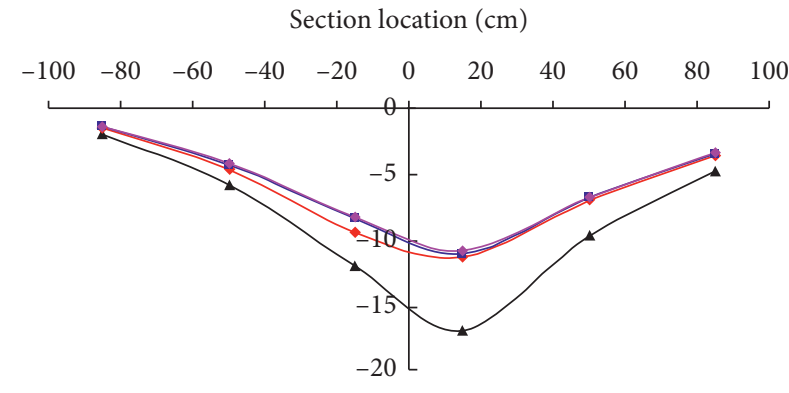

Third principal stress (MPa)

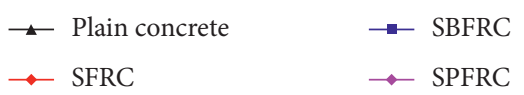

(b)

FIgure 8: The principal stress. (a) The first principal stress. (b) The third principal stress.

modulus, $\mu$ represents Poisson's ratio, $\varepsilon$ represents strain, and the subscript of $\varepsilon$ represents the angle of strain flower.

By extracting the maximum value of the first and third principal stresses for each working condition, the antibreaking effect of fiber reinforced concrete lining (relative to the plain concrete lining) was calculated (see Table 8).

According to Figure 8 and Table 8,

(1) After the test, the peak values of the first and the third principal stresses of the structure caused by the fracture slip dislocation are all located in the hanging wall, and the main stress of the hanging wall tunnel structure is more affected by the slip dislocation than that of the footwall.

(2) The antibreaking effect of the principal stress of fiber reinforced concrete lining (working condition 2-4) has a good antifault effect, up to $30 \%-40 \%$. The antibreaking effect of the first principal stress is better than the third.

(3) The antibreaking effect of the principal stress of hybrid fiber reinforced concrete lining (working condition 3-4) is better than that of steel fiber reinforced concrete lining (working condition 2). The antibreaking effect of SPFRC (working condition 4) is the best, and SBFRC (working condition 3 ) is slightly better.

4.2. Longitudinal Strain. Compared with static state, the increase multiple of the longitudinal strain of the structure caused by the stick-slip dislocation is calculated by extracting the measurement data of the longitudinal strain gauge of each measurement section after the test of each working condition (see Figure 9).

By extracting the maximum value of the increase multiple of the longitudinal strain in each working condition, the antibreaking effect of fiber reinforced concrete lining (relative to plain concrete lining) was calculated (see Table 9).

According to Figure 9 and Table 9,

(1) After the test, the peak value of the increase multiple of the longitudinal strain of the structure caused by the stick-slip dislocation is located in the hanging wall, and the influence of the stick-slip dislocation on the longitudinal strain of the hanging wall tunnel structure is greater than that of the footwall.

(2) The antibreaking effect of longitudinal strain of fiber reinforced concrete lining (working condition 2-4) is $80 \%-90 \%$. The longitudinal strain fault resistance 
TABLE 8: Antibreaking effect of principal stress.

\begin{tabular}{lcccc}
\hline $\begin{array}{l}\text { Working } \\
\text { condition }\end{array}$ & $\begin{array}{c}\text { Maximum value of the first } \\
\text { principal stress (MPa) }\end{array}$ & $\begin{array}{c}\text { Antibreaking effect of the first } \\
\text { principal stress (\%) }\end{array}$ & $\begin{array}{c}\text { Maximum value of the third } \\
\text { principal stress (MPa) }\end{array}$ & $\begin{array}{c}\text { Antibreaking effect of the third } \\
\text { principal stress (\%) }\end{array}$ \\
\hline 1 & 4.54 & - & 16.72 & - \\
2 & 2.93 & 35.42 & 11.63 & 30.42 \\
3 & 2.80 & 38.44 & 10.97 & 34.37 \\
4 & 2.77 & 38.96 & 10.81 & 35.32 \\
\hline
\end{tabular}

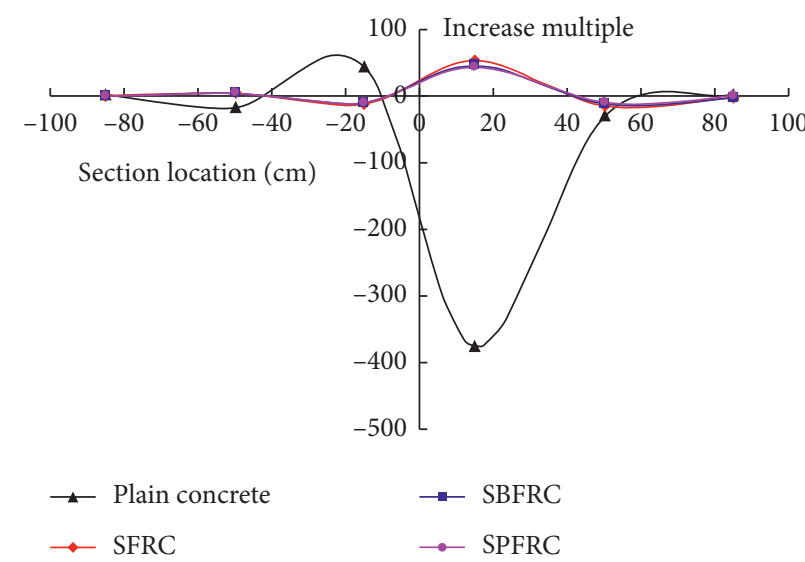

(a)

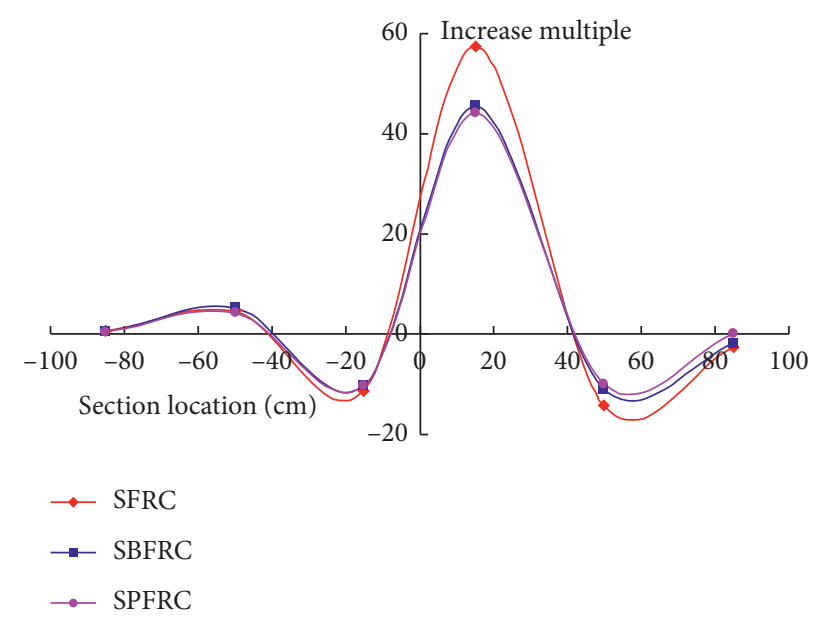

(b)

FIGURE 9: Increase multiple of longitudinal strain. (a) Working condition 1 4. (b) Working condition 2 4.

TABLE 9: Antibreaking effect of longitudinal strain.

\begin{tabular}{lcc}
\hline Working condition & Maximum value of increase multiple of longitudinal strain & Antibreaking effect \% \\
\hline 1 & 376.39 & - \\
2 & 57.32 & 84.77 \\
3 & 45.52 & 87.91 \\
4 & 44.06 & 88.29 \\
\hline
\end{tabular}

of hybrid fiber reinforced concrete lining (working condition 3-4) is better than that of steel fiber reinforced concrete lining (working condition 2). Working condition 4 (SPFRC) has the best antibreaking effect of longitudinal strain, which is slightly better than working condition 3 (SBFRC).

4.3. Contact Stress. Compared with the static state, the increase multiple of contact stress caused by the stick-slip dislocation was calculated by extracting the measurement data of the micropressure box at the measurement points of the arch crown of each measurement section after the test of each working condition (see Figure 10).

By extracting the maximum value of increase times of contact stress in each working condition, the increase percentage of the maximum value of increase times of contact stress in fiber concrete lining (relative to that in plain concrete lining) was calculated, as shown in Table 10.

According to Figure 10 and Table 10,
(1) After the test, the contact stress of the hanging wall is larger than that of the footwall, which indicates that the influence of the stick-slip dislocation on the contact stress of the hanging wall tunnel is larger than that of the footwall.

(2) As fiber reinforced concrete has the mechanical characteristics of reinforcing and toughening, the effect of fiber reinforced concrete lining on limiting the stress release of surrounding rock is stronger than that of plain concrete lining. The maximum value of the increase multiple of the contact stress in working condition 2-4 is higher than that in working condition 1 , and the increase percentage reaches $20 \%-30 \%$.

(3) Among the three kinds of fiber reinforced concrete, SPFRC has the weakest strengthening effect and the best toughening effect, and the maximum value of contact stress increase multiple in working condition 4 is the smallest, which is 38.53 times; SFRC has the 


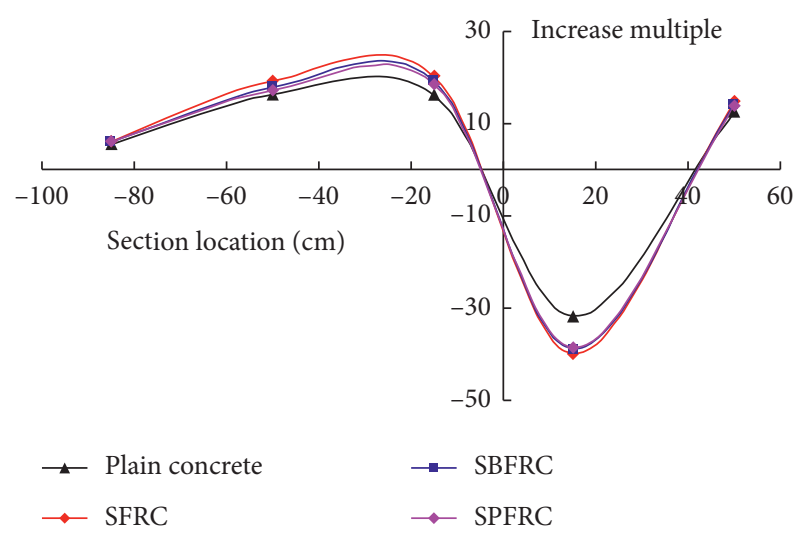

Figure 10: Increase multiple of contact stress.

TABLE 10: Increase percentage of maximum value of increase multiple of contact stress.

\begin{tabular}{lcc}
\hline $\begin{array}{l}\text { Working } \\
\text { condition }\end{array}$ & $\begin{array}{c}\text { Maximum value of increase } \\
\text { multiple of } \\
\text { contact stress }\end{array}$ & $\begin{array}{c}\text { Increase percentage } \\
(\%)\end{array}$ \\
\hline 1 & 31.76 & - \\
2 & 39.94 & 25.76 \\
3 & 38.76 & 22.03 \\
4 & 38.53 & 21.32 \\
\hline
\end{tabular}

best reinforcing effect and the weakest toughening effect, and the maximum value of increase multiple of contact stress in working condition 2 is 39.94 times.

4.4. Structural Internal Force. After the test of each working condition, the measurement data of the lateral strain gauge inside and outside the measuring points of each monitoring section vault are extracted, and the safety factor of the structure was calculated, as shown in Figure 11.

The compressive strength of axial and eccentric compression members with rectangular section is $[20,21]$

$$
K N \leq \phi \alpha R_{\mathrm{a}} b h .
$$

The tensile strength of the eccentric compression member with rectangular section is

$$
K N \leq \phi \frac{1.75 R_{1} b h}{6 e_{0} /(h-1)} .
$$

In the formula, the width of the section is expressed by $b$, and the width of the section is $1 \mathrm{~m}$. The thickness of section is expressed by $h$. Structural axial force is expressed by $N$. The ultimate compressive strength of concrete is expressed by $R_{\mathrm{a}}$. The ultimate tensile strength of concrete is expressed by $R_{\mathrm{l}}$. The ultimate tensile strength of coefficient of components is expressed by $\varphi$. The influence coefficient of axial force eccentricity is expressed by $\alpha$. The eccentricity is expressed by $e_{0}$.

By extracting the minimum value of the safety factor of each working condition, the increase multiple of the minimum value (relative to the plain concrete lining) was calculated, as shown in Table 11.

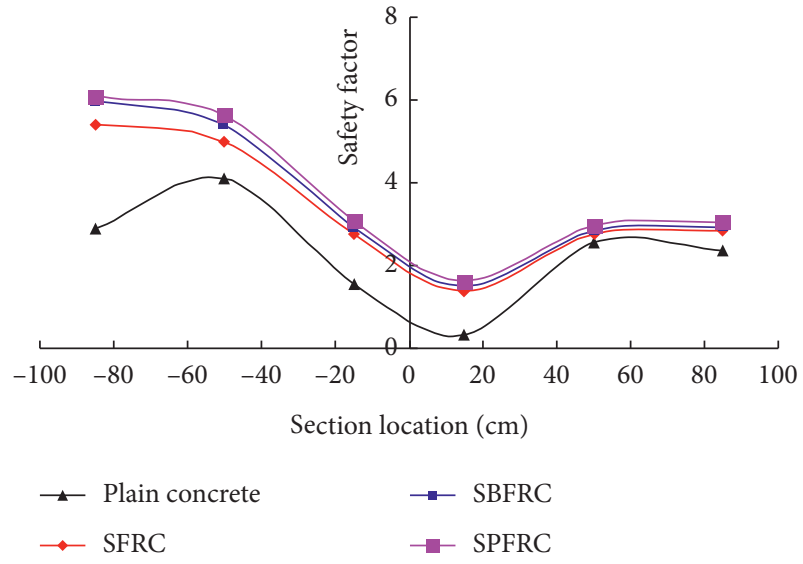

Figure 11: Safety factor.

TABLE 11: Increase multiple of the minimum value of the safety factor.

\begin{tabular}{lcc}
\hline $\begin{array}{l}\text { Working } \\
\text { condition }\end{array}$ & Minimum value of safety factor & $\begin{array}{c}\text { Increase } \\
\text { multiple }\end{array}$ \\
\hline 1 & 0.33 & - \\
2 & 1.39 & 4.22 \\
3 & 1.55 & 4.68 \\
4 & 1.62 & 4.89 \\
\hline
\end{tabular}

According to Figure 11 and Table 11,

(1) After the test, the minimum value of the structural safety factor of each working condition is located in the part of the hanging wall tunnel, which shows that the influence of the stick-slip dislocation on the internal force of the hanging wall tunnel structure is greater than that of the footwall.

(2) The minimum safety factors of SFRC, SBFRC, and SPFRC lining structure are $1.39,1.55$, and 1.62 , respectively, which are $4.22,4.68$, and 4.89 times higher than the minimum safety factors of plain concrete lining structure $(0.33)$. The minimum increase multiple of the structural safety factor of hybrid fiber reinforced concrete lining (working condition 3-4) is better than that of steel fiber reinforced concrete lining (working condition 2).

(3) The compressive strength of hybrid fiber reinforced concrete lining (working condition 3-4) is weaker than that of steel fiber reinforced concrete lining (working condition 2), the toughness is stronger than that of steel fiber reinforced concrete lining, and the structural safety is better than that of steel fiber reinforced concrete lining. Therefore, in the aspect of improving the antibreaking performance of tunnel, the toughening effect of fiber reinforced concrete is stronger than that of reinforcing.

\section{Conclusions}

(1) Under the condition that the fiber content is the same as the volume, SFRC has a slightly better 
strengthening effect than SBFRC and SPFRC; SBFRC and SPFRC have a better toughening effect than SFRC; SBFRC has a slightly better strengthening effect than SPFRC, and SPFRC has a slightly better toughening effect than SBFRC.

(2) The results show that the antibreaking effect of the principal stress of the fiber reinforced concrete lining is $30 \%-40 \%$, and the antibreaking effect of the first principal stress is better than the third. The antibreaking effect of the longitudinal strain is $80 \%-90 \%$. The maximum increase percentage of the contact stress is $20 \%-30 \%$. The minimum increase of the structural safety factor is 4-5 times.

(3) The principal stress, longitudinal strain, and internal force of hybrid fiber reinforced concrete lining (SBFRC and SPFRC) are better than steel fiber reinforced concrete lining, and the antibreaking safety of SPFRC lining is the highest.

(4) The compressive strength of the hybrid fiber concrete lining is weaker than that of the steel fiber concrete lining, the toughness is stronger than the steel fiber concrete lining, and the structural safety is stronger than that of the steel fiber concrete lining. Therefore, in terms of improving the antibreaking performance of the tunnel, the toughening effect of fiber concrete is stronger than the reinforcing effect.

\section{Data Availability}

The data used to support the findings of this study are included within the article.

\section{Conflicts of Interest}

The authors declare that there are no conflicts of interest regarding the publication of this paper.

\section{Acknowledgments}

The authors appreciate the support from the National Natural Science Foundation of China (nos. 51408008 and 51478277).

\section{References}

[1] S. Ardeshiri-Lajimi, M. Yazdani, and A. Assadi Langroudi, "Control of fault lay-out on seismic design of large underground caverns," Tunnelling and Underground Space Technology, vol. 50, pp. 305-316, 2015.

[2] M. J. Avanaki, A. Hoseini, S. Vandani, and A. L. Fuente, "Numerical-aided design of fiber reinforced concrete tunnel segment joints subjected to seismic loads," Construction and Building Materials, vol. 170, no. 5, pp. 40-54, 2018.

[3] M. J. Avanaki, A. Hoseini, S. Vandani, C. Santos, and A. L. Fuente, "Seismic fragility curves for vulnerability assessment of steel fiber reinforced concrete segmental tunnel linings," Tunnelling \& Underground Space Technology, vol. 78, no. 8, pp. 259-274, 2018.

[4] W. Xiong, W. Fan, J. Peng, L. Deng, and F. Yan, "Numerical analysis of effect of normal fault activity on road mountain tunnel project," Chinese Journal of Rock Mechanics and Engineering, vol. 29, no. 1, pp. 2845-2852, 2010.

[5] X. Liu, X. Wang, and L. Lin, "Model experimental study on influence of normal fault with $60^{\circ}$ dip angle stick-slip dislocation on mountain tunnel," China Civil Engineering Journal, vol. 47, no. 2, pp. 121-128, 2014.

[6] M. Russo, G. Germani, and W. Amberg, "Design and construction of large tunnel through active faults: a recent application," in Proceedings of the International Conference of Tunneling and Underground Space Use, pp. 16-18, Istanbul, Turkey, October 2002.

[7] A. R. Shahidi and M. Vafaeian, "Analysis of longitudinal profile of the tunnels in the active faulted zone and designing the flexible lining (for Koohrang-III tunnel)," Tunneling and Underground Space Technology, vol. 20, no. 3, pp. 213-221, 2005.

[8] X. Liu, B. Guo, X. Li, and Y. Sang, "Model experiment study on effect of deformation joints on road tunnel resisting destruction by thrust fault stick-slip dislocation," Chinese Journal of Rock Mechanics and Engineering, vol. 34, no. 2, pp. 3837-3843, 2015.

[9] Y. Liu and F. Gao, "Experimental study on the dynamic characteristics of a tunnel-crossing fault using a shake-table test," Journal of Vibration and Shock, vol. 35, no. 12, pp. 160-165, 2016.

[10] D. Wang, G. Cui, and J. Yuan, "Model experimental study on effect of reducing dislocation measures undering stick-slip fault dislocation of tunnel," Chinese Journal of Geotechnical Engineering, vol. 40, no. 8, pp. 1515-1521, 2018.

[11] M.-N. Wang and G.-Y. Cui, "Establishment of tunnel damping model and research on damping effect with model test in highly seismic area," Rock and Soil Mechanics, vol. 31, no. 6, pp. 1884-1890, 2010.

[12] S.-S. Wang, B. Gao, C.-Y. Sui, and Y.-M. Wen, "Mechanism of shock absorption layer and shaking table tests on shaking absorption technology of tunnel across fault," Chinese Journal of Geotechnical Engineering, vol. 37, no. 6, pp. 1086-1092, 2015.

[13] L. Liu, Y.-F. Wang, F. Liu, and J. Zhou, "Shaking table model tests on the influence of fault strike on the seismic responses of tunnels," Journal of Vibration and Shock, vol. 36, no. 21, pp. 196-202, 2017.

[14] G. Cui, D.-Y. Wang, S.-Z. Ni, and J.-X. Yuan, "Model tests on bearing characteristics of steel fiber-reinforced concrete lining of weak surrounding rock tunnel," Chinese Journal of Geotechnical Engineering, vol. 39, no. 10, pp. 1807-1813, 2017.

[15] G.-Y. Cui, D.-Y. Wang, S.-Z. Ni, and J.-X. Yuan, "Model tests on bearing characteristics of basalt fiber-reinforced concrete tunnel linings," Chinese Journal of Geotechnical Engineering, vol. 39, no. 2, pp. 311-318, 2017.

[16] Dalian University of Technology, CECS 13-2009, Standard Test Methods for Fibre Reinforced Concrete, China Planning Press, Beijing, China, 2009, in Chinese.

[17] Ministry of Housing and Urban-Rural Construction of the People's Republic of China, GB50010-2010 Code for Design of Concrete Structures, Ministry of Housing and Urban-Rural Construction of the People's Republic of China, Beijing, China, 2010, in Chinese.

[18] Ministry of construction of the people's Republic of China, Standard for Test Method of Mechanical Properties of Ordinary Concrete: GB /T 50081-2002 [M], China Building Industry Press, Beijing, China, 2003, in Chinese.

[19] C. L. Xin, Z. Z. Wang, J. M. Zhou, and B. Gao, "Shaking table tests on seismic behavior of polypropylene fiber reinforced 
concrete tunnel lining," Tunnelling and Underground Space Technology, vol. 88, no. 1, pp. 1-15, 2019.

[20] China Architecture \& Building Press, GB50157-2013 Code for Design of Metro, China Architecture \& Building Press, Beijing, China, 2013, in Chinese.

[21] China Communications Press, JTGD70-2004 Code for Design of Road Tunnel, China Communications Press, Beijing, China, 2004. 